RUNNING HEAD: Disclosure Model

\title{
Disclosure strategies among sex offenders: A model for understanding the engagement process in groupwork
}

\author{
Andrew Frost ${ }^{1}$ \\ Ken Daniels ${ }^{2}$ \\ Stephen M. Hudson ${ }^{3}$
}

\footnotetext{
${ }^{1}$ Author to whom correspondence should be sent: Dr Andrew Frost, Lecturer, School of Social Work and Human Services, University of Canterbury, Private Bag 4800, Christchurch 8140, New Zealand

Phone: $\quad+64-3-3642987$ xtn 8449, Fax: +64 - 3 - 364 2498; Email: andrew.frost@canterbury.ac.nz
}

${ }^{2}$ K. R. Daniels, Associate Professor, School of Social Work and Human Services, University of Canterbury, New Zealand

\footnotetext{
${ }^{3}$ Dr S. M. Hudson, Former Associate Professor in Clinical Psychology, University of Canterbury, New Zealand

Dr Hudson died in November 2001. His invaluable contribution is recognised here in terms of his active involvement in the conceptual thinking that informed this article.
} 


\begin{abstract}
A key component of the functional engagement of child sex offenders in a group-based programme is the disclosure of certain personal information. Such information is required to be of a type and presented in a way that facilitates open exchange in the group, promoting understanding of the presenter's offence pattern and conveying his sole responsibility for the offending. The model explained in this paper, based on an outcome from a grounded theory study, describes in detail four distinct orientations to such disclosure. Each is associated with a particular style of managing the disclosure encounter. Three of these disclosure management styles can be described as essentially "resistant” in nature, but only one is overtly oppositional. The two other "resistant" styles of disclosure management emerge as more covert and perhaps less readily identifiable expressions of reluctance. The implications of the model for work with this population and in more general settings are discussed.
\end{abstract}

Key words: engagement; child sexual offenders; disclosure management style; groupwork. 


\section{Introduction}

Over the past 30 years there has been considerable clinical and research attention paid to the issue of child sexual offenders' rehabilitation. Programmes addressing this need are well established and it is now generally considered that they can be effective in both prison and community settings (Marshall, Jones, Ward, Johnston and Barbaree, 1991; Marshall and McGuire, 2003; Polizzi, MacKenzie and Hickman, 1999). Efforts to develop and refine the effectiveness of these programmes have conventionally been focused on their content; that is, on establishing the targets of change, and the application of procedure and technique. However, particularly in the last five years, attention has begun to be directed toward matters relating to the context and process of intervention (see, for example, Fernandez and Marshall, 2000). Generic factors such as therapist style (Marshall and Serran, 2004) or the quality of groupwork (Jennings and Sawyer, 2003) as the prime modality in this work are examples of this trend.

These developments have focused attention on a constellation of client “responsivity” factors (Andrews and Bonta, 1998) that have long been the concern of practitioners but have until more recently resulted in little analysis. These factors are referred to in the literature under such labels as “disclosure” (Kear-Colwell and Pollock, 1997), “engagement” (Authors own, 2004; Levenson and McGowan, 2004), “resistance” (Mann, 2000), 
“denial” (Marshall, Thornton, Marshall, Fernandez and Mann, 2001) and “motivation” (McMurran and Ward, 2004; Tierney and McCabe, 2002).

Attention to this constellation of generic factors has resulted in the more systematic consideration in sex offender treatment of broader research and theory surrounding planned and assisted personal change. A commonly occurring theme across this broader literature is that elements of process are among the most critical to success (Hubble, Double and Miller, 1999; Prochaska and DiClemente, 1982). More specifically, the importance of the confidence, commitment, and collaborative participation of the client in the change process are stressed. Clear client authorship and ownership are cited almost universally as essential pre-requisites in the various forums in which change might take place (Mahoney, 1991; Miller and Rolnick, 1991; Prochaska and DiClemente, 1982).

Attention to these factors in their application to the prevention of sexual offending has also resulted in a more critical and analytical approach to context and process matters than was formerly the case. For instance, the notion of client resistance tended to be construed in terms of a twodimensional, relatively constitutional characteristic of offenders (Salter, 1998). The orthodoxy of this view has been questioned (Kear-Colwell and Pollock, 1997) and resistance has been reconceptualised as a more elaborate, nuanced and dynamic construct (Mann, 2000). More recent literature has also sought to present a client perspective in these matters. 
However, the theoretical work in this area has predominantly emphasised the deductive application of psychological theory and constructs, especially from the cognitive-behavioural area. Similarly, research studies on client responsivity matters have tended to rely on the importation of concepts established in other contexts, using predefined constructs that are assumed to be relevant to sex offender’s motivations (e.g., Pfäfflin et al., 2005). Importing such constructs may fail to accurately capture the experiential responses of these clients in context, thus compromising validity.

The consideration of planned change as a staged process, involving the client system as the primary active agent in that process, has long been part of the social work tradition, as has the principle of starting "alongside" the client (Compton et al., 2005). These notions were central to a study (Authors own, 2004) the aim of which was to investigate the engagement of sexual offenders undertaking group therapy. The research was carried out at Kia Marama, a successful prototypical group treatment programme, using a relapse prevention-based approach in a prison setting (Hudson, Wales and Ward, 1998). In the course of this study a procedure was developed to access the covert responses of participants at critical moments in this encounter. In this way the study sought to elicit the "immediacy" of the client experience, resulting in a capture of data with a high degree of fidelity to the construct. The theoretical model proposed in this paper is based on a key outcome from this research. 
The attention to matters beyond content and procedure has in part been a response to the recognition of the need to fully engage participants in the change process. In a challenging and active process of personal change, “engagement” represents more than mere consent to intervention. A social work approach relies on a collaborative and reflexive involvement with the potential client in exploring, planning around, and addressing presented issues. The notion of engagement is foundational to this process. Critical to engagement is client readiness to reveal aspects of experiential and often private ways of knowing the world.

In the case of sexual offender work, engagement is particularly concerned with personal acceptance of and responsibility for change. Rehabilitation programmes for sexual offenders commonly invite participants to engage in a high level of self-disclosure surrounding their abusive conduct. This is generally seen as ultimately critical to making the changes necessary to addressing re-offending risk, and is therefore a primary requirement of offender treatment programmes (Barker and Morgan, 1993; Marshall, 1999). A groupwork modality (Barker and Morgan, 1993; Beech and Fordham, 1997) is the common approach to offender work, and provides the therapeutic context where such disclosure takes place in these programmes.

The disclosure management model, generated from the Kia Marama research, represents the set of response styles revealed by clients of the programme, when challenged to self disclose. The focus for the study was the programme module addressing offence pattern (“offence chain”) 
disclosure, and the attendant processes of group feedback and refinement. It was considered that this component of the Kia Marama programme provided the best opportunity to explore responses to engagement efforts. In order to illuminate and explore the interpersonal processes at work in the therapy group, observations were sought from the perspective of the individual facing the challenge of self-disclosure at the actual time of this key encounter.

A detailed description of the methodology used in the study appears elsewhere (Author's own, 2004). However, a brief description is provided here.

\title{
The Research Study
}

\author{
Methodology
}

The direct research objective was to identify personal and interpersonal factors impacting on the therapeutic engagement of individuals, and to explore the group processes contributing to those factors. The intention was to assess events salient to individual research participants as they occurred in the context of the group. These events, along with self-reported experiences, were then to become the subject of ongoing analysis.

In order to attempt to access the direct experiences of participants, a variation of the "articulated thoughts” method (Davison, Robins and 
Johnson, 1983) was used. These data were developed using a grounded theory analysis.

\section{Research Participants}

Participants were incarcerated offenders convicted of one or more sexual crimes against persons under the age of 16 . Prior to their inclusion in this study, each had volunteered to undertake the Kia Marama programme, which is administered by the Psychological Service of the New Zealand Department of Corrections. The treatment facility is attached to a standard 60-bed low-medium security prison unit at Rolleston in the province of Canterbury. Inmates accepted for treatment were transferred to Rolleston from regional prisons. Over the course of the study, treatment groups were commencing every one to two months. The ages of the 16 primary participants ranged from 23 to 65 with a mean age of $40.2(S D=12.7)$. The convictions of this group involved indecent assault, unlawful sexual connection, and sexual violation. Two were Maori and 14 were of Pakeha (non-Maori, generally European) ethnicity. Length of sentence ranged from 24 to 72 months, with the mean being $40.3(S D=14.8)$. Number of victims ranged between one and eight, with a mean of $2.75(S D=2.2)$. None of the primary participant group had a current psychiatric illness, although five had psychiatric histories.

Procedure 
Treatment intake groups targeted for inclusion in this research were approached and invited to take part in the study. Participation involved being videotaped during a group therapy session, journaling personal responses to the session, and taking part in a follow-up research interview. Given the presence of the participant's fellow group members at the time of the index session, consent from each of these persons was also necessary. Where such dual consent was gained, each primary participant was videotaped in the context of the group treatment session dedicated to eliciting details of the participant's offence chain.

Following the index group session, the participant was asked to carry out a series of tasks. The central aspect of these tasks involved identifying and recording details of salient experiences during the session. Prior to the next treatment session the participant identified from the video recording those episodes he had nominated. For this part of the study the participant was invited to recall the circumstances of the previous session and to vividly imagine himself back in that situation. The salient episodes from therapy selected by the participant were then identified and re-played as sections of video in the presence of both participant and researcher. Each of the episodes was started and stopped (freeze-framed) at frequent intervals in order for the man to articulate his subjective experiences (to "think aloud”) throughout significant parts of the encounter. He was encouraged to elaborate thoroughly on these experiences throughout each viewed episode. This interview was audio-recorded, transcribed, and considered alongside other data for grounded theory analysis. 
Analysis

Analysis was largely conducted according to Strauss and Corbin’s (1990) grounded theory approach. Interview transcripts were collected, one batch at a time, as successive treatment groups passed through the relevant stage in the programme. On each occasion the transcripts were broken down to discrete “meaning units”. Each meaning unit was initially labeled with a note relating to its semantic quality and the units were then grouped together as categories according to these labels. As this proceeded, the categories were condensed into clusters to capture and combine categories of similar meaning. The process of collating categories was followed by preliminary attempts to identify potential relationships between them. Data continued to be assigned to categories as each data source was placed alongside existing categories for comparative analysis. The relationships validated from this process directed subsequent data collection.

Employing Strauss and Corbin's (1990) axial coding paradigm, which defines the elements of a causal sequence and applies them to the categories of data, these procedures gradually revealed a narrative. The evolving narrative came to describe how participants in the study "navigated” a pathway through the disclosure session according to their expectations and subsequent experience of the session. As analysis by these means progressed, the central principle to this navigation process was tested and confirmed as the "core” category (Strauss and Corbin, 1990). This core 
category related to the men's shared central concern with performing to a set of expectations ("getting it right"). While the nature of such expectation varied between the men, this common concern appeared axiomatic to the emerging account of how clinical engagement occurred. Once this was discovered, the process of what was going on when participants confronted the disclosure encounter could be described in terms of a flowing, sequential account. Moreover, each of the primary participants’ narrative accounts could then be identified in terms of seeking to address this concern. Data testing eventually reached a stage of "saturation" (Strauss and Corbin, 1990), where all newly culled units of meaning were codable into the existing categories.

The resulting narrative accounts were found to fall into four broad categories, resulting in four disclosure management styles. The model describing these styles is described in the next section.

\section{The Disclosure Management Model}

A significant outcome of this study was to suggest that participants in the research were confronting the various risks and opportunities they perceived in the disclosure encounter according to a recognisable dynamic process. Essentially, orientation to the task of disclosure appeared to be founded on certain predispositional factors (surrounding expectations, hopes and fears) brought to the encounter by participants. Subsequently, participants were observed to adopt particular goals and strategies with respect to these risks 
and opportunities. These goals and strategies manifested in a set of distinctive response styles. Response styles were, in turn, seen to be characterised by certain markers of progress, sources of influence and subsequent responses as participants experienced events salient to them during the session.

Figure 1 represents a graphic simplification of the resulting disclosure management model. It presents the two dimensions of goal and strategy, and the four broad disclosure orientations that they generate. The combinations and permutations of these goals and strategies form the basis for understanding the construct of disclosure orientation. Moreover, we argue, disclosure orientation helps us understand how engagement takes place in this instance.

According to this model, disclosure goals relate to matters of personal validation and, particularly, to the principle source of such validation. Where the individual puts greater emphasis on the evaluation of others (characterised here as an "external” influence) he is said to be otherdirected. Alternatively, where the man takes a self-validating approach (an “internal” influence) he is considered to be self-directed.

The self/other continuum intersects with the second dimension of Figure 1: the disclosure strategy continuum. This describes the active responses of participants to the challenges that the session represents to them. The extremities of the strategy continuum are construed as “open” and "closed”. 
That is, in the course of the disclosure encounter, opportunities are created for sharing ideas, hypotheses, suggestions, enquiries, advice and explanations. Whereas some clients favour relative openness to such exchange of information during the session, others are seen to adopt a circumspect approach (“closed”).

Figure 1 about here

Disclosure management style then can be viewed, in this instance, as the stance adopted by the man that characterises his approach to engagement in the disclosure encounter. Each of these four styles is described below using illustrative data from the study.

The Exploratory Style (self-directed, open strategy)

According to the model, some clients emphasise the attainment of selfvalidated (“internally”-sourced) outcomes from the disclosure encounter. That is to say, they are inclined to set goals that are concerned with prioritising their own needs directly, as opposed to deferring to the expectations they may perceive from others during the course of the encounter. A proportion of these clients combine this propensity with a strategy of pro-active openness to exchange, supporting a free flow of 
assertions, questions, observations, disputations, and other forms of information.

This disclosure management style is associated with a curiosity-driven, collaborative predisposition, and participants who emphasise this style seek to manage the encounter with a spirit of enquiry, and a reflective and considered attitude to feedback.

Emerging issues are met with a discovery-driven, pro-active stance, as they endeavour to build on or to modify pre-existing understandings. There is an expectation that other group members will engage actively, fully and mutually in a synergism.

The fact that being a group, and being a number of people that are working together, there is aiding and abetting each other to get more ideas. It's just a feeling I get that the group is better as a whole than just the parts. It's like a magnetic force linking all the people together. The group will work together to get it.

\section{(Participant G)}

Fellow participants are typically seen as the means by which internallymotivated goals are pursued. Their value is seen in terms of their ability to contribute to the accretion of information, giving rise to a felt sense of accumulating knowledge, or insight. Their attention is therefore drawn to those who are perceived to exhibit the sort of personal qualities that 
substantiate the validity of their contribution, such as genuineness, inquisitiveness, authoritativeness, relevance, and reliability.

The questions keeping coming helped things.

When...he asked: "Oh, what happened here”; or, "what

did happen there?” it jogged my memory, helped me

think of other things, keeping me on track. (Participant

G)

The influence of the role and function of others is a relevant issue in at least one other way here. The degree to which fellow participants reveal similar or congruent experiences reflects their potential to shed light on one’s own situation, or helps to inspire mutual trust.

D went about that in a helpful way. He realised my situation. I think he worked it out, and he compared [my situation] to when he became dependent. He brought a lot of his views. (Participant K)

We get on well. We talk a lot about what has happened with our offending - they are sort of similar, in some aspects. And it was good to talk to him, and I always listen to what he has to say. (Participant Q)

The men make an active effort to identify markers (features, events, etc.) that discriminate between past understanding and new understanding, 
contributing to a dawning or evolving sense of illumination and clarity about themselves and their offending.

In this case, everyone knows what is expected of each other. Everybody is working towards the same goal, namely to help each other: to uplift, working towards a common goal. We all know that everyone knows that everyone will be in the hot seat... all working in the same team towards a common goal. OK, as an individual, I’ve got my own point of view, my own kind of thinking, and my own way of doing things; as part of the group I get a feed from round the group and my ideas expand, I feed the group, and so on. I am this big [gesturing] as an individual, and that much bigger [expansive gesture] as part of the group (Participant G)

Full, on-task participation is expected of others; participation that is free of collusion, pity or misplaced sympathy.

He is talking about me falling into a snare. It was like because he was talking about himself - he is falling into a snare. Hey, I never fell into a snare! I did what I did because I did it all. It wasn’t, “Whoops! I'm here, I’m offending!” But that is what he seems to be getting at. Like, he was trying to get me on his side, about the idea of falling into this snare. (Participant K) 
Oppositional Style (Self-Directed / Closed Strategy)

The oppositional style stands in stark contrast to the exploratory disclosure management style. It is associated with an orientation characterised by reflexive resistance.

Where an “internally”-sourced locus of demand combines with a closed approach to communication, the prospect of change is considered differently. Invitations to engage in a critical analysis of one’s account are viewed at best with suspicion or disdain, and at worst as a form of hostility. This often generates anger.

I felt that he's not believing me; this is not me up there on the [white-] board.... He was trying to make it the truth, something that it wasn't. He was twisting it all around, changing the outcome of it.... I think it was a lot of bullshit - constructing something that's not there! (Participant P)

The therapy process is presumed to be a controlling technology. Intervention is typically considered a form of manipulation. The therapy forum is perceived as having an adversarial tone, and a power struggle is anticipated. The clinician is typically viewed in the role of a teacher, judge, or cunning interrogator.

I suppose that is what his job is, to try and see if he can change your mind, or have another thought about it. 
Perhaps seeking me to become uneasy about the situation, that I might say something I might not have said previously, or to try to get me angry; I'm not quite sure.... He is trying to make you feel uncomfortable; he is trying to get you to say something that possibly might not have intended to say. Well, it doesn't affect me that way! (Participant P)

The stance appears to contribute to a process of locking the individual into a reluctance to consider an outside perspective:

Here I am, giving it my best shot, being quite upfront about it, and he’s trying to shoot me down in flames! There is no point in me not coming clean, what have I got to gain or lose by it? - Nothing! Hell's teeth! It has done all the damage; I have to rebuild my whole life situation again now! .... He perhaps doesn’t know me all that well, and therefore he is entitled to that criticism, perhaps. If he knew me better, then he probably wouldn't have said that. (Participant P)

Most critically, these participants seek to promote and rigidly maintain initial positions and propositions, actively resisting alternative constructions. A siege mentality is adopted: a position is taken, defences constructed, and “attacks” repelled. 
[Therapist] was saying that I was making a whole lot of choices. This was getting me hot! I didn’t put that up onto my [offence] chain, I left it blank. I had no planning and I said I had no feeling; but [Therapist] is saying that I did make choices, pointing at the board, and telling me I did! (Participant B)

If somebody is going on to me a bit like that, I'll probably sit and listen to them but I'll probably give them a comment after. (Participant P)

The interpersonal approach in the course of the encounter is one marked by self-sufficiency. Feedback is scrutinised for criticism, and alternative constructions tend to be refocused to the man's original account.

What he is trying to do is say, "Because this happened in your life and because that happened in your life, it has caused you to do this”. My reaction to that - and I told him straight - I knew how I offended and why I offended, and I knew how I felt at the time and straight after it, it is all on the chain there, it's all there. (Participant P)

Success in "scoring points" over those who are seen to oppose them is the benchmark of progress for those who take this approach. The session is seen as a competitive encounter, and the outcome is in terms of a binary measure 
of whether one's position is held or is compromised; won or lost. Others, therefore, are identified either as ally or as adversary.

There, E, I thought, was getting on my wavelength. I thought I was with the mother, not the [victim]. And here is someone who has an idea of what really did happen.... I had in mind that some of them were agreeing, eventually, with [Therapist]'s point of view. I think they all had ended up with [Therapist]'s point of view. (Participant B)

That was M talking about his drinking and blanking out and losing time. I think: "Here is someone like myself me! M - he knows what I done. You're not letting him have his say! What is the point - you're not believing me!” (Participant B)

Feedback is evaluated according to its conformity to or deviation from an original position, and accepted or dismissed on that basis. The consideration of feedback is therefore subject to early foreclosure

$\mathrm{J}$ was talking about his experiences, and he was opening words with "I find it hard to believe..." And he has a pen in his hand. At that moment I was pretty hot and riled.... (Participant D) 
I feel kind of defensive: $\mathrm{C}$ is leaning forward, he is pointing his pen, and I want to say, "Shut up!” I am feeling this guy has too much to say. (Participant D)

Response to such skirmishes depends on the participant's evaluation of which contention has prevailed. Given the dichotomous way in which the encounter is viewed, this equates to a sense of being believed or disbelieved; understood or not understood.

I’m thinking, “Are you sure you are listening, reacting?” He doesn't understand my experience here. He doesn’t know my thinking, he hasn't understood what I meant.... Riling me again, because I'm not bloody believed.... I felt condemned by [Therapist] Ya, he’s not believing my side, he’s only believing his own. (Participant B)

When [Therapist] says to me, "How did you turn it into a sexual assault?” I got very defensive. My arms were crossed; I was just trying to holding myself in - hold myself together. I felt quite aggressive, defensive... and I'm being stirred up and not being believed. (Participant D)

In summary, these participants appear primarily concerned with and committed to holding a position. Because a key tool of intervention is to 
promote alternative perspectives, impasse is a typical outcome. The meeting of this irresistible force and immovable object yields, even in the most optimistic construction, a failure to promote functional engagement. At worst it appears the outcome may be that the initial reluctance is actively entrenched.

Evasive Style (Other-Directed/Closed Strategy)

The core features of the evasive style orientation are a fear of negative evaluation and an inclination to adopt a strategy of concealment or deception. Those who hold it tend to cite a concern with exposure to shame.

Here [the offence] is being exposed for everybody; stuff even I've hidden from myself. It is bloody terrifying. (Participant $\mathrm{H}$ )

A key predispositional feature is pronounced ambivalence. Those who adopt this orientation appear to be both drawn to the benefits of disclosure and repelled by a fear of experiencing the distress associated with humiliation.

I think I was hoping for a miracle: that I would understand [my offending] without being uncomfortable. But unfortunately they don’t go together. I knew that, I was aware of that. I wanted to understand it, but I was pulled both ways, I didn’t want 
the discomfort and the personal hurt of talking about it. (Participant F)

There is an assumption that a vulnerable, subordinate self will be confronted by authority-based and ultimately irresistible influences.

Right here I see [Therapist] as doing his job, doing exactly what he is supposed to do. I felt that, deep down - I have always been aware - that [Therapist] would get to the bottom of it eventually.... I couldn't [achieve this] on my own. With [Therapist] if you try and veer off, he puts you straight back on; he is direct. With the rest of the group, they will check you. (Participant F)

Others present in the encounter are generally perceived as threatening because they represent critical and compelling forces insisting on the public exposure of sensitive matters.

The most terrifying thing in here in this room with these people - the worst thing about it - is how they feel about me. (Participant $\mathrm{H}$ )

Evasion is, then, a self-protective strategy. In attempting to balance the competing demands for personal disclosure on one hand, and the avoidance of distressing exposure on the other, the men endeavour to supply responses 
that will provide the minimal amount of genuine information they consider will appear to meet perceived demands.

I was starting to get - it was getting towards the end of the session, and I was starting to get saturated with it. And I felt we had gone over and over and over this topic, and I was starting to look for a way out of this topic. I was trying to think of a way I could answer it and get on with it in a way that it wouldn't give him something else to dig for. I wanted to answer the question, but I didn't want to leave it open to give him the opportunity to go off on another tangent relating to it. (Participant F)

Tactically, these participants are seen to resort to a range of subterfuges designed to evade or avoid the disclosure of information that is considered “personal” (shame-inducing).

I was tired: I feel as if at that stage there I was trying to justify; I was making it sound less than what it really was.... I was trying to make it sound as if it was not as bad as what it really was.... I was looking for the answers; I was trying to think of answers [Therapist] would accept as suitable answers. (Participant M) 
These subterfuges include deflection, attempts to influence the use of session time, and side-tracking:

I told [Therapist], “Yes, I was,” just to get off the hook. I attempted to say that to move things along. I was keen to give him the answers he wanted to hear, to move on.... I didn't want to get stuck on this stuff (Participant H)

In their attempts to minimise their exposure to shame, some of the men resort to brevity or truncation in their responses.

[To relieve the discomfort] I was tempted to get back to short, brief answers; try not to elaborate. (Participant F)

In order to counter the threat of being caught off-guard, and consequently supply “incriminating” responses, some engage in pre-session preparation and rehearsal, or seek to second guess challenges during the session itself.

I had it in my mind that everybody was waiting for my answer because I left [sexual] "Fantasy” out of the [offence] chain. I left it out on purpose because I didn't want to talk about it. (Participant H)

I was trying to mind-read, of what the guys were going to think of me. And what I thought was, “They're not 
going to believe this.” I'm focused straight on

[Therapist] right here - trying to read [Therapist], but struggling. (Participant E)

Impression management is used to disguise distress, or other emotional responses which may threaten to reveal the real self.

The number of things I am getting angry about is accumulating [but] I hid things very well. I'm a great person for reading people. I took courses in body language. I’ve leaned back from him, I have my legs crossed away from him, I’m chewing on my pen. (Participant $\mathrm{H}$ )

[Therapist] was sitting there asking about the impact on victims. I was mainly concentrating on what [Therapist] was saying - avoiding the other guys. (Participant C)

...it was coming up like a gusher. I was trying to keep it down because men don't cry. (Participant C)

Sometimes such tactics are perceived to fail. They enter the encounter having anticipated a range of personally damaging contingencies, often having planned responses to these contingencies in a desperate attempt to avoid the expected harm. On being confronted with the objects of these 
fears in the course of the encounter, they typically experience an urge to physically escape the situation

....and the gut feeling was I was starting to boil a bit, get frustrated, angry, uncomfortable, squirmy and anxious.... When this happens to me I want to be anywhere else but in the room. (Participant $\mathrm{J}$ )

This participant confronts a dilemma. The therapy session is construed as an ordeal, and emotional survival is considered paramount. While motivated to access the benefits of therapy, he is primarily anxious to avoid any explicit association between himself and qualities that are potentially stigmatising. The solution is to attempt to finesse his way through the encounter, avoiding both shame on the one hand and failure on the other.

Placatory Style (Other-Directed/Open Strategy)

Those participants who, during the disclosure encounter, emphasise a placatory management style exhibit a primary concern with attracting interpersonal support by presenting in a favourable or sympathetic light. To this end, their conduct often suggests an ostensibly commendable level of self-disclosure. They are vigilantly aware of the presence of others and conscious of the fact that they are continuously generating a socially evaluated impression. The need to manage this impression is an immediate concern and tends to override more self-directed priorities. 
They had some questions that I had to answer, because they might think I was hiding, and that I wasn’t actually telling the truth on the [offence] chain. And I would be lying to myself: that is something that you have to keep down, and try not to remember it. (Participant A)

The importance of "telling the truth" during the disclosure process, from this perspective, lies in the imperative of appearing compliant. In this way one may avoid social censure.

It is a bit about getting out the truth. Because it is important to get out the truth - yeah - and it is important to be honest with the group. If you are not honest, they pick up the same things [Therapist] picks up. You know if you are telling the truth or telling a lie, [Therapist] will pick it up and so will the group. (Participant N)

“Getting it right”, in this instance then, is about meeting expectations of others present, at least according to appearances:

I wasn't worried about that - more worried about what was up on the [white-]board, and worrying if it was right - if it was put down right in the right place. And saying it right. I just read out what was put down there, 
and what was down there - was it right? What I was thinking about there at the time. And if [Therapist] put it on the board, that meant it was right. Yeah, when it was up there, it was right. If [Therapist] didn’t put it on the board, it means I must have done something wrong with the answer that was down there. (Participant A)

As with the evasive disclosure management style, the placatory style is associated with an ambivalent motivation toward therapy. Unlike the former, however, the tension here lies between the urge to meet explicit expectations of openness, honesty and directness on the one hand, and the need to create a sympathetic image on the other. Disclosure for the purposes of therapeutic insight, or for its own sake, is risky:

Wanting to talk about what you were actually doing, the offending - I didn't think I could actually say that; I was wondering what the group was thinking about me.

This tension creates a bind. If the man yields to the demand for personal transparency he is likely to be forced to reveal socially unattractive qualities. Efforts to resolve this bind may give rise to considerable stress.

...to find the right words - It was hard work [pause] hard work.... And I knew then that I was being told off, and I didn't feel very good. And I thought he really is serious, and he's going to ask me a really serious 
question, which he did. And I felt like a naughty boy in

school. As though I had done something wrong and I was expecting to be punished for it. (Participant A)

The therapeutic process is considered an exercise in external evaluation, as if taking place before a judge and jury. An interrogative process, as might be experienced in a court of law, is typically anticipated.

This is like the lawyer asking the questions.... This, here, is like the court, 'cause there you have to tell the truth, and the rest of the group are sort of like a jury and [Therapist] is like a judge. They make up their minds and ask the questions. (Participant N)

Considerable attention is given over to monitoring the social evaluation of self.

J doesn't judge me, he just points out the fact that what I should have done. I wouldn’t mind being judged by him, he has a lot of things he wants to tell me, but he doesn't judge me. And that's bad in some ways, because you want to be judged by your peers: judged on what I say in the group about the chain; judged, say, like whether you are a good guy or a bad guy. So you really want to know what J really thinks. Ya, what he and the group really think about me. (Participant N) 
Interpersonal information that is seen to have a bearing on the legitimacy of their accounts of themselves is monitored with especial vigilance for indicators of acceptance or rejection.

It was accepted by [Therapist]; he would have said if he hadn’t accepted it. [Therapist] turns back to the board there, and I've got a sense of relief for me that he has gone to the board to address the board and put whatever I had answered him on the board. And think about it of how he had put it on the board for the group to see. A relief that I've come out with the right answer. [Had I got it wrong,] I would have felt put down because my thinking was wrong. I led [Therapist] to believe that - I led him to believe that I was just thinking it was all right to do that what I did. I was quite relieved that I got away with that answer, and explained to the group that I have changed over the last ten years. (Participant A)

In terms of a disclosure strategy, there are again similarities with the evasive style, in that this approach is dominated by the principle of impression management. But the emphasis in the current context is more on the approach goal of winning the approval of others than on the avoidance goal of insulation from emotional harm. Unlike the tactics of the former approach, here expansion tends to be preferred over minimisation; elaboration over brevity. 
They were just asking, and I was trying to be honest.

Get it out with the group, get it out of myself. I have a lot of things that I had done in the past; and all I needed were the right questions, and give the right answers.... (Participant A)

If they thought I weren’t telling the truth, then I would have to explain it to the group another way, until they believed in what I actually put - said on the board. They would have known if it was not the truth, they would have said. So it was important that it was right. (Participant N)

In this endeavour to satisfy the perceived demands of others, the form of responding is as important as the content of the response. However, rather than wishing to appear nonchalant and unaffected (as in the case of the evasive style), there is an intention to convince that one is being actively open, direct and honest.

...it was very important that I got this explained out correctly to the group, because it was probably one of my bad parts of my offending.... And it was good because he wanted an explanation, and I am there to give explanations. And I have psyched myself up before, after seeing all these others go through the 
group, that I wanted to be able to be free and easy and get it all out.... I can see I'm scratching my arm, sitting forward; [Therapist] is sitting back. I sat forward, which I did quite a bit, to prove that I am taking interest in what is going on. (Participant A)

A sense of urgency is regularly presented to convey the impression of honest spontaneity.

I was engrossed in the question put to me and getting a suitable explanation out correctly. And probably a little bit apprehensive that I wasn't going to get it out properly and get them to understand. I was worried that if it didn't come out properly that I would be looked down upon. I think that offending against young children is worse than offending against ones that are a bit older.... (Participant A)

Progress is measured by events and perceptions that suggest to the participant that he has gained a measure of interpersonal acceptance. This may be indicated by favourable appraisal, or feedback that is seen to be emotionally supportive, affirming, reassuring or sympathetic. Those events that provide information on their social approval level are the key sources of information for these participants. The group is seen as a mirror in which their presentation is reflected and their acceptability measured. In observing the responses of others, elements of form are likely to be attended to before 
elements of content. For instance, the identity of the respondent or the manner of his response is attended, sometimes at the expense of the literal intent of his message. And it is the voice and manner of power and authority that impresses these participants most of all.

W comes through here the strongest of all the members, he's the most outspoken. It's like he’s the leader, and I felt that what he said, he meant; he meant what he said. I took more notice of what W said. He's not like me, he’s very assertive, he’s very strong. He’s just this authority figure. (Participant L)

W and A would have more impact than M. M is a bit like me, very shy and reserved. You wouldn't get the same feedback from him. So he would be more closed. M wouldn't have the same impact as W and A.... It's not that I disbelieve him - he’s a bit furtive, he’s a bit like me. And I don't feel like I'm going to get the same feedback from someone like me. (Participant L)

Where the participant perceives continued threat from unfavourable evaluation by others, he is likely to remain reluctant to commit himself to self-disclosure.

There was one thing in my offending I didn’t talk about, but it wasn't that bad. [pause] Well, it was bad 
in a way, but it wouldn't have to come out in the group.

(Participant N)

I was thinking there that if I told the truth, the whole truth - like what when I took my clothes off; what I actually [did] do. Did I do more than what I had written down there on paper...? - and so forth. And it just clicked in my in my mind: "If I did...” - and I thought, "No! This was exactly what I wrote down, so I will go with that.” (Participant N)

A typical response to the perception of negative appraisal is to attempt to repair perceived damage or smooth over any conflict. Open and honest disclosure is an unlikely outcome in this instance also.

He was looking directly at me and expecting a straight reply. [But] I probably had a feeling that I was still being a bad boy; and a feeling of being a nobody, and getting myself into trouble. I've had that feeling all the time. I was aware at the time, that other people were looking at [Therapist], and I was also expecting the eyes to be on me until I came up with an answer. It felt like the full focus was going to be on me. I was totally engrossed in finding an answer. I was focusing on giving [Therapist] a completely right and true answer 
because I wanted to. I had to go through my mind and find the right words. It was a little bit stressful to find the right words.... I wanted to avoid his direct eye contact while I sought an answer. (Participant A)

In summary, there exist similarities between the placatory disclosure management style and the evasive style. For instance, while in fact both approaches are concerned with the goal of satisfying the expectations of others, participants of either persuasion may, in certain circumstances attempt to convey an impression of being self-directed. However, the distinguishing feature of action associated with the placatory style is the concern with securing emotional support. The goal here is to have oneself acknowledged, heard, affirmed; in short, to be acceptable to others. In contrast to the strategy associated with the evasive style (which emphasises reactive attempts to close down a flow of information), here there is a proactive focus on creating a favourable impression. The emphasis is on aligning oneself with others rather than insulation from emotional harm. Of course, to accept fully the identity of a child molester is likely to be viewed as inviting threat to positive evaluation. However, immediate social survival tends to be valued above the intra-personal risks associated with personal disclosure, and there is a danger that these men may accede to inaccurate accounts of themselves or their behaviour purely for the purpose of avoiding rejection in the immediate context. Personalities and relatedness are important catalysts to therapeutic engagement here, as favourable conditions 
are created when the experience of social approval is paired with therapeutically relevant disclosure.

\section{Discussion}

Some of the implications of this model have been discussed elsewhere (Authors own, 2004). The following section develops this discussion, especially with respect to implications for practice.

Implications of four styles of disclosure management for therapeutic engagement

The disclosure management model, as presented above, suggests that different clients adopt different approaches to the challenge of disclosure. It also suggests that it is possible to identify discernible patterns in the approaches and to classify them according to one of four disclosure management styles. Each of these styles can be considered with regard to its functionality in respect to therapeutic engagement.

Attitudes and postures brought to therapy by participants plainly influence the course of their engagement in the disclosure process. It is also clear that, for many, this forestructuring is significantly motivated by fears, reflecting concerns surrounding the emotional harm anticipated to result from selfdisclosure. Fears of being isolated or discriminatorily exposed appear to be common. Where these concerns are prominent, participants often revert to practices that run counter to functional engagement. Active responses are in 
the form of evasion, opposition or appeasement; core features of three of the four disclosure management styles. Nevertheless, most of these clients reveal a degree of ambivalence in their motivation, and apparently recognise that their predicament represents opportunity as well as threat.

A motivation common across all four disclosure management styles is the imperative of securing personal acceptability. Some participants emphasise “internally”-sourced criteria of acceptability, where progress toward selfdiscovery appears to both drive and satisfy this desire. This position is a central feature of the exploratory style. In this instance, when exposed to alternative perspectives, the individual takes up a stance of self-referenced curiosity, motivating relatively uninhibited and active enquiry. However, the quest to attain acceptability, for members of other categories, tends to be achieved at the expense of this open and direct approach to self-disclosure. For these participants, anxiety about revealing themselves to this degree arises when they contemplate abandoning the strategies with which they have habitually and enduringly sought to secure social acceptability in the past. We found that, in these cases, the prospect of involvement in a process where such open exchange is required motivates responses that are, again, unfavourable to functional engagement. Here, suspicion drives hostility, fear drives defensiveness, and neediness drives unconditional “compliance”. For many then, exposure to alternative accounts of themselves and their behaviour is predominantly experienced as threatening. These men, in this context, tend to direct their attentional resources and their efforts toward those events that speak to them of harm. 
According to this model, the accurate assessment of disclosure management style is useful in understanding how to promote functional engagement in the group. Early assessment of disclosure management style could make treatment more efficient and effective by obviating time-consuming and profitless confrontation. With intervention informed by a knowledge of disclosure orientation, offenders may learn alternative ways of promoting their interests by engaging in collaborative practices and thereby freeing up resources, which can be put to better use.

In this respect, it is important that clinicians develop and promote an empathic response to the participant's perceptions of personal and interpersonal risks related to self-disclosure, especially the ways in which he attempts to protect himself or in other ways to advance his goals. A salient point here is the powerful role that the therapist is seen to occupy by participants. Clearly, for many, this is a factor that invites responses that are more to do with impression management or defensiveness than promoting the understanding of offending. Therapists should be aware of this power, acknowledge it as a factor, and seek ways to nullify the unhelpful influences evident in the data from this study.

More general implications

The intention of the study on which this model is based was to explore the behaviour of individuals within the group. However, there are also implications for the group as a systemic whole. The promotion of an overall 
climate of openness in group settings is likely to be well rewarded. Interpersonal transparency appears desirable, along with feedback encouraging the reflections of group members on how they view the fact of the disclosures and what new light they may see the individual in. Where such information is not made explicit, clients appear motivated to invest energy and resources unproductively in attempting to infer the evaluation of others. In an optimal group climate (see Beech and Fordham, 1997) such interpersonal feedback would be both sensitive and useful to the discloser. Enhanced transparency may assist in neutralising mistrust and avoidance, and may therefore encourage self-disclosure in relevant domains. We recommend promoting open but sensitive speculation by the group on the values and intentions of the discloser in a manner that opens opportunities to revise his actions in relation to his intentions.

Such practices may empower clients to identify their sense of agency and personal accountability. This provides a possible counter to any inclination toward passivity or apathy, and a way of promoting personal responsibility for risk-management.

In order to establish a climate of mutual curiosity, we suggest that a context of safety needs to be established and manifestly demonstrated in the group. For clients to participate in open and direct disclosure, as well as attending to challenging feedback, a forum for promoting interpersonal acceptance should be established. This needs to be reflected in the general sub-culture of the service facility as a whole, alongside the notion of strengthening the community of concern around the issue of sexual offending. 
The model suggests that a clinical approach communicating acceptance and respect for the whole person should be maintained within a climate of lowered intensity around personal disclosure. It lends support to the argument of Fernandez and Marshall (2000) that treatment providers should pay serious attention to such contextual matters.

\section{Conclusions}

The early and accurate identification of disclosure management style in clinical settings may promote more efficient and effective use of therapy time.

A key task for treatment providers perhaps is to establish the sort of clinical context that is most likely to attract commitment to open and direct selfdisclosure. As clinicians we must attune more sensitively to client phenomenology in relation to the experience of disclosure. More specifically, we need to attend to the concerns and the experiences of the disclosing person. Thus, we can respond more effectively to promote engagement.

We also need to make explicit the often covert goals and strategies of disclosure management. From early in the life of the group, the matter of disclosure orientation could be introduced into the group’s discourse. Participants could be schooled in the recognition of disclosure management styles and encouraged to discuss their own inclinations. This can be achieved in the stages of group formation and norm building where the issue 
of establishing group cohesiveness is prominent. In short, this requires making self-disclosure an issue within the treatment process.

The challenge of engaging child sexual offenders in a rehabilitative programme is in neutralising suspicion, fear and false expectation, and thereby weakening the antagonism, deception, and misdirected energies that they drive. In this way, perhaps groupwork in this field will become closer to the collaborative endeavour it ought to be.

\section{References}

Andrews, D. A. and Bonta, J. (1998). The Psychology of Criminal Conduct ( $2^{\text {nd }}$ ed.). Cincinnati, Anderson.

Barker, M. and Morgan, R. (1993). Sex Offenders: A Framework for the Evaluation of Community-Based Treatment. London, Home Office.

Compton, B. R., Galaway, B., and Cournoyer, B. R. (2005). Social Work Processes ( $7^{\text {th }}$ ed.). Belmont, Brooks/Cole-Wadsworth.

Davison, D. C., Robins, C., and Johnson, M. K. (1983). Articulated thoughts during simulated situations: A paradigm for studying cognition in emotion and behavior. Cognitive Therapy and Research, 7(1), 17-40.

Fernandez, Y. M., and Marshall, W. L. (2000). Contextual issues in relapse prevention treatment. In D. R. Laws, S. M. Hudson and T. Ward (Eds.), Remaking Relapse Prevention with Sex Offenders: A Sourcebook. Thousand Oaks, Sage. 
Frost, A. (2004). Therapeutic engagement styles of child sexual offenders in a group treatment program: A grounded theory study. Sexual Abuse: A Journal of Research and Treatment 16 (3) pp.191-208.

Frost, A. \& Connolly, M (2004). Reflexivity, reflection, and the change process in offender work. Sexual Abuse: A Journal of Research and Treatment 16 (4) pp.365-380.

Hubble, M.A., Duncan, B.L., and Miller, S.D. (Eds.). (1999). The Heart and Soul of Change: What Works in Therapy. Washington DC, American Psychological Association.

Hudson, S. M., Wales, D. S., and Ward, T. (1998). Kia Marama: A treatment programme for child molesters in New Zealand. In W. L. Marshall, Y. M. Fernandez, S. M. Hudson, and T. Ward (Eds.), Sourcebook of Treatment for sexual Offenders. New York, Plenum. Jennings, J. L. and Sawyer, S. (2003). Principles and techniques for maximising the effectiveness of group therapy with sex offenders. Sexual Abuse: A Journal of Research and Treatment, 15(4), 251-267.

Kear-Colwell, J., and Pollock, P. (1997). Motivation or confrontation: which approach to the child sex offender? Criminal Justice and Behavior, 24(1), 20-33.

Levenson, J. S. and Macgowan, M. J. (2004). Engagement, denial, and treatment progress among sex offenders in group therapy. Sexual Abuse: A Journal of Research and Treatment, 16(1), 49-63.

Mahoney, M. J. (1991). Human Change Processes: The Scientific Foundations of Psychotherapy. New York, Basic Books. 
Mann, R. E. (2000). Managing resistance and rebellion in relapse prevention intervention. In R. Laws, S. Hudson, and T. Ward (Eds.), Remaking Relapse Prevention With Sex Offenders: A Sourcebook. Newbury Park, Sage.

Marshall, W. L. and McGuire, J. (2003). Effect sizes in the treatment of sexual offenders. International Journal of Offender Therapy, 47(6), 653-663.

Marshall, W. L. (1999). Current status of North American assessment and treatment programmes for sexual offenders. Journal of Interpersonal Violence, 14(3), 221-239.

Marshall, W. L. and Serran, G. A. (2004). The role of the therapist in offender treatment. Psychology, Crime and Law, 10(3), 309-320

Marshall, W. L., Jones, R., Ward, T., Johnston, P., and Barbaree, H. E. (1991). Treatment outcome with sex offenders. Clinical Psychology Review, 11, 465-485.

Marshall, W. L., Thornton, D., Marshall, L. E., Fernandez, Y. M. and Mann, R. (2001). Treatment of sexual offenders who are in categorical denial: A pilot project. Sexual Abuse: A Journal of Research and Treatment, 13(3), 205-216.

McMurran, M. and Ward, T. (2004). Motivating offenders to change in therapy: An organizing framework. Legal and Criminological Psychology, 9, 295-311.

Miller, W. R. and Rollnick, S. (1991). Motivational Interviewing: Preparing People to Change Addictive Behaviour. New York, Guilford. 
Pfäfflin, F., Böhmer, M., Cornehl, S. and Mergenthaler, E. (2005). What happens in therapy with sexual offenders? A model of process research. Sexual Abuse: A Journal of Research and Treatment, 17(2), 141-151.

Polizzi, D. M., MacKenzie, D. L. and Hickman, L. J. (1999). What works in adult sex offender treatment? A review of prison- and non-prisonbased treatment programs. International Journal of Offender Therapy and Comparative Criminology, 43(30), 357-374.

Prochaska, J. O. and DiClemente, C. C. (1982). Transtheoretical therapy: Toward a more integrative model of change. Psychotherapy: Theory, Research and Practice, 19, 276-288.

Salter, A. C. (1988). Treating Child Sex Offenders and Victims: A Practical Guide. Newbury Park, Sage.

Tierney, D. W. and McCabe, M. P. (2002). Motivation for behavior change among sex offenders: A review of the literature. Clinical Psychological Review, 22(1) 113-129. 